DOI: $10.14451 / 1.166 .48$

\title{
ОРГАНИЗАЦИЯ УПРАВЛЕНИЯ ДИНАМИЧНЫМ ПРОИЗВОДСТВОМ БОЕВОЙ АВИАЦИОННОЙ ТЕХНИКИ В ТУРБУЛЕНТНОЙ ЭКОНОМИКЕ
}

\author{
(c) 2018 Базадзе Наталья Григорьевна \\ доктор экономических наук, профессор \\ профессор кафедры «Менеджмент и маркетинг высокотехнологичных отраслей промышленности» \\ Московский авиационный институт (Национальный исследовательский университет) \\ 125993, г. Москва, Волоколамское шоссе, 4 \\ E-mail: n-bazadze@yandex.ru
}

Организация управления производством авиационной техники в условиях турбулентной среды обеспечивается сквозным организационным проектированием процессов хозяйственной деятельности корпораций и распределением ответственности по всем уровням управления и работникам корпоративных структур.

Ключевые слова: турбулентная экономика, авиастроительные корпорации, организационное развитие, сквозное организационное проектирование, организационно-управленческие компетенции, организация коллективного трудового процесса.

\section{1. Глобальная конкуренция}

Производство новой боевой авиационной техники в конкурентной мировой экономике привлекает все большие объемы финансовых и материальных ресурсов, поддерживая паритет стран - основных конкурентов на рынке боевой авиации последних поколений. На вооружение российской армии принято более 300 новых образцов военной техники, обеспечивающих высокий уровень обороноспособности страны [1]. С декабря 2017 года первое авиационное формирование в Южном военном округе (ЮВО), оснащенное МиГ-31 с гиперзвуковым ракетным комплексом «Кинжал», приступило к несению опытно-боевого дежурства, в том числе и по акватории Черного моря, куда 1 мая этого года вошли корабли военно-морской группы НАТО. Высокоточный авиационный ракетно-космический комплекс, отличается высокой маневренностью, малой радиолокационной заметностью и гиперзвуковой скоростью (до 10 махов), защищающей его от перехвата средствами противовоздушной обороны [2]. По данным Интерфакс - АВН от 29.04.2018 летчики-истребители авиационного полка Западного военного округа (3ВО), получили на вооружение первую партию многоцелевых истребителей поколения «4+» Су-30СМ [3]. Эти самолеты обладают - высокой маневренностью, многофункциональностью, сниженной эффективной поверхностью рассеивания (малозаметностью), радарами с фазированной антенной решеткой, двигателем с управляемым вектором тяги. Самолет пятого поколения, получивший в 2017 году индекс СУ-57, оснащенный авиационным вооружением нового поколения, проходит сейчас заключительные испытания оружия в воздухе и в этом же году ожидается его поступление в строевые части.

Конкуренция на мировом рынке боевой авиации обостряется в сегменте истребителей пятого поколения, первый представитель которых F-22 Raptor был принят на вооружение в США еще в 2011 году. Лётные испытания проходят ещё три модели конкурирующих между собой истребителей 5-го поколения трех ведущих держав боевых самолетов: F-35 (США), ПАК ФА (Россия) и J-20 (Китай). Самым дорогим истребителем 5-го поколения, является многоцелевой истребитель F-22 Raptor, серийное производство которого началось в 2001 году. Как отмечает [4], ссылаясь на данные Главного контрольного управления США (GAO) - к концу 2010 года себестоимость одного самолёта F-22 по полному циклу затрат достигла 411,7 млн. долларов. Дальнейшие стратегии развития боевой авиации различные эксперты связывают с развитием гиперзвуковой авиации, созданием ударных беспилотников, разработкой истребителей 6-го поколения, перспективных комплексов дальней авиации, многофункциональных авиационных комплексов. К более смелым прогнозам относят разработки, основанные на квантовой телепортации. Так, в рамках программы «Национальная 
технологическая инициатива» (НТИ), созданной Агентством стратегических инициатив (АСИ), в 2025-2035 предусматривается «внедрение нейроинтерфейса, квантовых вычислений, телепортации, использование природоподобных явлений для передачи информации». [5]. При любом направлении развития боевой авиационной техники авиастроительные корпорации останутся крупнейшими хозяйствующими субъектами в экономиках конкурирующих государств. Уровень их социальной ответственности продолжает возрастать перед федеральными и региональными структурами управления, населением собственных стран, персоналом своих предприятий и членами их семей.

Учитывая значимость отрасли для национальной безопасности стран-производителей боевой авиации, объемы финансирования ее производства постоянно возрастают. Оптимизация затрат на производство новой техники при возрастающих требованиях к ее эффективности становится не разовой задачей, а постоянной функцией авиастроительных корпораций - функцией организации управления авиастроительным производством.

\section{2. Зоны ответственности в турбулент- ной экономике}

Решать возрастающие по сложности задачи организации управления производства новой авиационной техники предстоит в условиях турбулентной экономики. Сегодняшняя мировая и отечественная экономика стоит на рубеже коренных изменений, поток которых нарастает почти в геометрической прогрессии. Динамика внешней среды характеризуется также разнообразием и высокой скоростью геополитических и внутриполитических перемен, перераспределением сфер влияния, социально-демографическими переменами, технико-технологическими инновациями, изменениями в образовательных и культурных предпочтениях и приоритетах. Однако угрозу для стабильного развития отрасли, являющейся локомотивом экономик многих стран мира, представляют не только сами изменения, их количество и скорость появления. Как известно, любое развитие предполагает изменения, прогнозировать которые позволяет современный математический аппарат - методы экстраполяции, математического и статистического моделирования, экспертные методы. Они по- зволяют получить достаточно точные прогнозы для относительно стабильных условий. Ситуация с турбулентной экономикой более точно описывается теорией катастроф.

Непредсказуемость, а, следовательно, угрозы для управления в стратегической перспективе представляют изменения поведенческой модели основных игроков глобального рынка. Турбулентность среды всегда проявляется в динамике изменения ее параметров во времени и пространстве. Турбулентность внешней среды для авиастроительных корпораций определяется изменениями векторов поведения крупных игроков - хозяйствующих субъектов и политических группировок. Влияние первых определяется масштабами их хозяйственной деятельности, определяющей силу давления на экономику - объемами потребляемых ресурсов, размерами капитала, объемами производства, численностью персонала, так и последовательностью управленческих действий (постоянства или смены направления развития), определяемых степенью свободы принимаемых решений. Основными характеристиками политических группировок являются: количество, масштабность и сила влияния, скорость развития, уровень интеграции действий участников как плотность группировки, постоянство и переменчивость коалиционных векторов. Сила давления среды становится столь высокой, что проникает через замкнутый контур управления оборонных структур. Соответственно развитие параметров внутренней среды и процессы, в ней протекающие, также испытывают хаотические флуктуации. Снижение их скорости, продолжительности и масштабов и является задачей организации управления стабильно развивающимся производством конкурентной авиационной техники.

Авиастроение в силу специфики длинноциклового производства требует стратегического подхода к управлению на длительную перспективу. Если стратегическое планирование занимает все более прочное место среди функций управлении авиастроением, то реализация стратегических планов - только начинает буквально отвоевывать себе место в управленческой занятости, которая в свою очередь, складывалась за последние десятилетия хаотически. При этом работа, с горизонтом стратегического планирования не отменяет требования оперативного управления производством. Органи- 
зация управления авиастроительным производством во внутреннем и внешнем контурах управления оказывает все более сильное давление руководительский корпус, который испытывает сейчас значительные перегрузки. Это давление возможно перераспределить между тремя группами участников процессов управления производством:

- традиционная группа - руководители всех звеньев управления;

- относительно новая группа - специалисты по организационному проектированию и развитию, но не внешние специалисты оргпроектных институтов, а внутренние специалисты - работники собственных подразделений авиастроительных корпораций;

- новая группа в российском авиапроме исполнители работ, обладающие высокой квалификацией в своей профессиональной области.

Многоуровневые структуры управления авиастроительных корпораций как самостоятельных хозяйствующих субъектов (таких как ПАО «Сухой», АО РСК «МиГ», ПАО «Корпорация «Иркут») предполагают выделение нескольких контуров управления хозяйственной деятельностью. Первый контур, отделяющий внешнюю рыночную среду от внутренней среды - разделяет зону ответственности руководителей высшего и среднего звена. Руководители высшего звена как топ-менеджмент корпоративной структуры работают в условиях высокой неопределенности внешней среды, в их сферу влияния входит не только стратегическое планирование работы своей службы, но и отслеживание изменений во внешней среде, влияющие на изменение функционала службы. Менеджмент как система управления предполагает реализацию управленческих решений, основанную на свободе предпринимательского выбора. Свобода предпринимательского выбора, свойственная топ-менеджменту корпоративных структур в сегодняшней экономике, сдерживается многими экономическими и политическими факторами, однако, в оборонном комплексе эти ограничения ужесточаются многократно, снижая угрозы безопасности страны. Методам современного администрирования - управления на основе норм и регламентов для создания единой корпоративной культуры, типизации и унификации не только технических, но и организационно-управленческих решений, уделя- ют значительно меньшее внимание. В то время как они убедительно доказали свою эффективность, за счет обеспечения трудовой и технологической дисциплины в различных системах хозяйствования. И сегодня крупные коммерческие структуры активно используют методы администрирования.

Менеджмент как стиль управления в корпорациях может быть реализован только на высшем уровне управления. Только на этом уровне руководители обладают определенной степенью вариативности в выборе управленческих решений. На этом уровне управления инструменты менеджмента наиболее эффективны. Средний и, особенно, низший уровень управленческого звена, ответственный за эффективные трудовые процессы непосредственных исполнителей, работают в поле административного управления, которое предполагает построение управленческих решений на основе комплексно-обоснованных стандартов, нормативов, планов и программ.

В этих условиях, основным назначением топ-менеджмента корпораций оборонной промышленности становится регулирование влияния внешней среды на корпорацию через взаимодействие с учреждениями и организациями, соответствующих профилю функционала соответствующей службы, которую возглавляет тот или иной руководитель топ-уровня. Однако, спускаясь на нижние уровни управления горизонт стратегических возможностей суживается. У руководителей среднего звена основной функционал сосредоточен на уровне тактического управления и предполагает сочетание методов менеджмента и администрирования. Назначение руководителей среднего звена транспонировать (переформатировать), принятые на верхнем уровне решения в процессы исполнения внутри корпорации, распределяя их между подразделениями низшего звена управления - первичными трудовыми коллективами. Руководители среднего звена - лидеры для руководителей первичных коллективов. Руководители низших звеньев управления выстраивают в своих подразделениях коллективные трудовые процессы непосредственных исполнителей работ на уровне рабочих мест. Наибольший объем их управленческих решений и действий находится в зоне оперативного планирования производством и процессами их обеспечения и обслуживания. 
3. Производственные процессы - как совокупность технологических и трудовых процессов

Реинжиниринг системы управления не допускает остановки производственных процессов и процессов всей хозяйственной деятельности корпораций. Сегодня в производственных процессах вся оптимизация сосредоточена на технологической составляющей, неупорядоченная трудовая составляющая и привносит хаотичность в поточное производство. Производственный процесс на предприятиях стал планироваться, нормироваться, контролироваться и анализироваться как чисто технологический процесс. Потеряна важнейшая составляющая производственного процесса - трудовая. Безусловно, на автоматических линиях в массовом производстве, при высоком уровне организации и автоматизации производства - это оптимальное решение. Однако, в военном авиастроении доля мелко-серийного и опытного производства весьма значительна. Здесь трудовые процессы основных и вспомогательных производственных рабочих - основной результирующий фактор, обеспечивающий качество и конкурентоспособность выпускаемой продукции. Все остальные функции организационных структур должны рассматриваться как обеспечивающие производство, соответствующими услугами и решениями в текущем и перспективном периодах. Следовательно, работу всего персонала предприятия: управленческого, инженерно-технического, обслуживающего следует организовывать как трудовые процессы, выделяя в ней повторяющиеся компоненты, которые подлежат стандартизации.

Понятие трудового процесса традиционно используется в области организации производства при организации труда производственных рабочих. Организацией труда специалистов занимался и занимается гораздо меньшее количество исследователей. Еще малочисленнее круг исследователей и проектировщиков трудовых процессов в сфере управления производством и производственными коллективами. В свое время научно-исследовательский институт труда разрабатывал общесоюзные рекомендации по управлению производственными коллективами, включая проектирование трудовых процессов. За рубежом аналогичные компетенции востребованы при подготовке специалистов по системам и процедурам, аналоги которых встречают- ся в российских корпорациях при оптимизации бизнес-процессов компаний.

Управление процессами предприятия как часть его динамичного развития становится в новых условиях неотъемлемой частью функционала не только руководителей всех уровней, но и каждого работника предприятия, ограниченного зоной ответственности по рабочему месту. Каждый работник предприятия должен не только владеть профессиональными компетенциями, но и организационными компетенциями - навыками и умениями организовывать собственный трудовой процесс и, что крайне важно в коллективном трудовом процессе, владеть методами менеджмента «сшивки» единичных трудовых процессов в общий коллективный трудовой процесс. У специалистов и рабочих число коммуникационных контактов значительно меньше, чем у руководителей. Их количество существенно возрастает по мере повышения уровня управления, на котором действует руководитель.

Рост вертикальной интеграции в авиастроении, высокий уровень кооперационных связей, наделяет персонал структурных подразделений корпораций и персонал предприятий - поставщиков комплектующих изделий, особым статусом - статусом стратегических ресурсов по двум основным причинам. Первая - эффективные трудовые процессы не только основных производственных рабочих, но и всех работников предприятия, приводят к созданию конкурентной продукции - не только по качеству, но и по затратам. В работе всех категорий работников есть повторяющиеся элементы, которые следует стандартизировать. Все процессы стандартизированной работы следует рассматривать как трудовые процессы и минимизировать по непроизводительным затратам. Творческая составляющая процессов деятельности различных категорий работников и комбинированные процессы требуют исследования, других форм и методов регламентации и подключения к организации управления ими самих исполнителей. Вторая - турбулентности внешней среды следует противопоставить внутреннюю упорядоченность за счет оптимизации коллективных трудовых процессов, выстраивая их как ламинарные потоки работ не только в первичных коллективах, но и по всей корпоративной структуре, включая межподразделенческие коммуникационные процессы и кооперационные процессы с поставщиками комплектующих. 
4. Новые требования к организации управления динамичным авиационным производством

Изложенные выше доводы позволяют сделать вывод - управление авиастроительными корпорациями как крупномасштабными организационно-техническими комплексами в новой турбулентной экономике может быть эффективно, если является:

1. широкосистемным и полносистемным рассматривающим как систему не только внутренний, но и внешний контур управления во всем объеме политико-экономических и социальных аспектов;

2. холистическим - корпорация как объект управления рассматривается как целостное организационное образование по составу входящих структурных единиц с общей философией и организационной культурой;

3. сквозным - управленческие решения, принимаемые на верхних уровнях управления должны транспонироваться на все нижние уровни в виде распределенных потоков технологических и трудовых процессов;

4. стратегически ориентированным - стратегическое планирование в авиастроительных комплексах необходимо подкреплять методически проработанным механизмом реализации и корректировки стратегических планов по структурным единицам и в целом по корпорации по приоритетам федерального, регионального и локального значения;

5. комплексно обоснованным - с учетом пространственных, временных, социальных, психофизиологических, стоимостных и нормативных параметров процесса;

6. ситуационным - оценка и оптимизация управленческих решений принимаются с учетом ситуации по временному отрезку текущего планирования с учетом состояния объекта в предшествующем и желаемого состояния в будущем периоде;

7. саморазвивающимся за счет ориентации на внутренние и внешние человеческие ресурсы - специфика и возможности длинно циклового производства авиационной техники и длительного жизненного цикла человеческих ресурсов должны быть синхронизированы и задействованы не только во внутреннем, но и внешнем контуре управления;

8. превентивным - управление рисками в крупно-масштабных комплексах необходимо выстраивать не столько с помощью финансовых инструментов, сколько мерами организационной защиты от рисков с помощью организационного планирования и организационного проектирования;

9. процессным - деятельность управляемого объекта рассматривается в динамике, как поток производственных: технологических и трудовых процессов;

10. профессионализированным - реализовываться профессионально подготовленными специалистами - в инженерной и производственной областях, программа подготовки которых включает блок организационно-управленческих дисциплин, как будущих руководителей производственных и инженерных подразделений и специалистами в области организации управления авиастроительным производством, как потенциальных работников подразделений по организационному развитию авиастроения.

В свою очередь, организация новой системы управления авиастроительными комплексами как крупномасштабных систем в условиях динамичных изменений экономико-политических условий их хозяйствования без остановки выпуска все более конструктивно-сложной продукции, может быть успешно реализована в рамках выделения новой функции и, соответственно, новой службы - организационного развития авиастроительных корпоративных структур. Ее основные задачи:

- объективный анализ текущего состояния состава и процессов реализации функций корпорации и подразделений в сопоставлении с результатами их хозяйственной деятельности;

- построение вариантов моделей обновленных составов функций и их разверстки в виде процессов во времени и пространстве;

- разработка сценариев и дорожных карт перехода от текущего состояния системы управления к проектируемому состоянию.

\section{5. Востребованность компетенций по} организации динамичного управления

В последние годы в крупных отечественных корпоративных структурах, как добывающих, так и перерабатывающих отраслей, вслед за крупным зарубежным бизнесом появляются специализированные подразделения, чей функционал посвящен реорганизации систем управления предприятиями на основе оптимизации процессов. Это подразделения по организации 
управления, организационному проектированию, организационному развитию. Частично данный функционал включен в зону функциональной ответственности таких подразделений, как:

- подразделения по стратегическому управлению;

- по развитию (интеграция функций развития бизнеса и организационного развития);

- по организационному развитию и управлению человеческими ресурсами;

- по оптимизации бизнес-процессов.

На рынке труда Москвы и Московской области за последние 5 лет наметилась устойчивая тенденция роста спроса (открытых вакансий) по должностям руководителей и специалистов вышеназванных подразделений. Заметна динамика роста предложений по тем же должностным позициям. При этом ни в резюме соискателей, ни в описаниях вакансий не указано наличие образования по данному профилю. Однако, учебных заведений, занимающихся в России подготовкой таких специалистов на сегодняшний день по государственным, отраслевым или корпоративным заказам не выявлено. Подготовкой специалистов по организации управления авиастроительными и ракетно-космическими корпоративными структурами на инициативной основе занимается Московский авиационный институт по направлению бакалавриата «Менеджмент», профиль «Организационный менеджмент».

В последние годы у лидеров боевого авиастроения, таких как АО «РСК «МиГ» и ПАО «Компания «Сухой», появились подразделения, занимающиеся развитием и преобразованием организационных структур и процессов управления производством. При единстве целей организационного развития - обеспечение гибкости и адекватности требованиям времени, состав функций, задач, методов решения и организационных форм их реализации значительно различается, что при отсутствии отраслевых разработок по организации управления обусловлено эмпирическими подходами руководителей и специалистов этих подразделений и высшего линейного руководства.

Программы управленческой подготовки наряду с традиционными дисциплинами менеджмента, маркетинга, корпоративного права, управления персоналом, финансового менеджмента, управления затратами должны быть дополнены дисциплинами, формирующими организационные компетенции - организация труда, проектирование трудовых процессов, организационные коммуникации, организация производства и управления, организационного планирования, организационного проектирования, организационного моделирования. При этом следует помнить, что все организационные компетенции успешнее осваиваются на реальных примерах выполнения обязанностей по функционалу того рабочего места, где сейчас трудится действующий работник или потенциального рабочего места, где планируется будущее рабочее место студента или обучающегося. Эволюционное развитие авиастроительных комплексов, существенно снижающее социальные риски, даже в условиях турбулентной среды возможно реализовать за счет использования инструментария организационного проектирования для реализации различных сценариев их стратегического развития. В отрасли, где проектирование летательных аппаратов, является ведущей дисциплиной, организационное проектирование как научная и учебная дисциплина практически не востребована. Проектирование систем управления авиастроительным производством ведется «на глазок», исходя из опыта и представлений ответственных за эту область лиц. Безусловно, что опыт как «сын ошибок трудных» в этой области весьма значим, но она давно уже заслуживает профессионализации - подготовки профессиональных специалистов в области организации управления производством. При этом, по мнению автора, при производстве такой продукции, как самолеты последних поколений, прямо противопоказан подход «общего менеджмента». Только объектно-ориентированное управление, предполагающее профессиональное знание объекта производства, сочетающее в составе управленческих инструментов, как методы менеджмента, так и методы администрирования, позволит обеспечить эффективное устойчивое долгосрочное развитие авиастроительного производства в России.

\section{6. Выводы}

1. Создавать и снижать уровень турбулентности внешней и внутренней среды управления в авиастроении способны только социальные группы, процессы эффективных коммуникаций с которыми рассматривается как составляющая часть конкурентных компетенций на долгосроч- 
ную перспективу.

2. Обеспечивать конкурентоспособность новой авиационной технике на длительную перспективу смогут конкурентоспособные корпоративные структуры. Разработку и выпуск новых поколений авиационных комплексов, не снижая темпов оперативного производства, обеспечит сквозное организационное проектирование процессов всей хозяйственной деятельности на всех уровнях управления, включая технологическую и трудовую составляющую, разделяя подходы к повторяющимся и инновационным видам деятельности.

3. Сквозное организационное проектирование процессов предполагает выделение и развертывание процессов не только на верхних уровнях управления корпораций и предприятий, но и на уровне подразделений и рабочих мест специалистов и рабочих.

4. Организационное проектирование и освоение оргпроектных разработок следует вести параллельно, вовлекая и интегрируя действующий и потенциальный персонал на стадии обучения последнего в профильных учебных заведениях, например, в рамках формата дуального обучения.

5. Проектирование летательных аппара- тов - ведущая дисциплина для выпуска новых образцов конкурентной продукции авиастроения, организационное проектирование как учебная и научная дисциплиной заслуживает особого места в системе организации управления конкурентным авиастроительным производством и программах профильных университетов.

6. Организационные компетенции, включая организацию эффективного трудового процесса, оптимизацию рабочего места и организационные коммуникации со смежниками - обязательная составляющая конкурентных компетенций для всех категорий работников авиастроительных корпораций в турбулентной среде.

7. Система организации управления производством конкурентной авиационной техники должна быть профессионализирована за счет создания университетских программ подготовки специалистов для служб организационного развития и начала подготовки кадрового резерва на руководящие должности на более ранних периодах в рамках модернизации программ инженерной подготовки в профильных университетах.

\section{Библиографический список}

1. Послание Президента РФ В.В. Путина Федеральному Собранию РФ от 1 марта 2018 г. ГАРАНТ.РУ: http:// www.garant.ru/hotlaw/federal/1182611/\#ixzz5QrwdsQТР Д.о.12.09.18

2. «Лисья гончая» «Кинжалом»: как МиГ-31 стал носителем гиперзвукового оружия. Военно-промышленный курьер. Общероссийская еженедельная газета. 3 апреля 2018 г. Д.о. 12.09 .18 https://vpk-news.ru/news/42017

3. Пешков А. Авиаполк в ЗВО получил звено новейших истребителей Су-30СМ. 10.09.18. Медиа-группа «Звезда» Д.о.15.09.18 https://tvzvezda.ru/news/opk/content/201809101539-xzzn.htm

4. Многоцелевой истребитель F-22 «Raptor». 10.04.2012 Военно-политическое обозрение «Третья мировая война». https://3mv.ru/publ/mnogocelevoj_istrebitel_f_22_raptor/5-1-0-9208

5. В России к 2035 году попробуют внедрить телепортацию. Наука и техника. Лента.pу. 22 июня 2016 https:// lenta.ru/news/2016/06/22/teleportation/

6. Глазл Ф., Ливерхуд Б. Динамичное развитие предприятия. Калуга, 2000 г.

7. Базадзе Н.Г. Концепция организационного проектирования как инструмента создания организационного механизма инновационной экономики предприятий авиационной промышленности // Вестник Московского Авиационного Института». 2010. № 4, том 17. 